\title{
The Role of the State in Resolving Business Disputes in China
}

\author{
Julan $\mathrm{Du}^{\mathrm{a} *}$ Yi Lu ${ }^{\mathrm{b}}$, and Zhigang $\mathrm{TaO}^{\mathrm{c}}$ \\ ${ }^{\mathrm{a}}$ Chinese University of Hong Kong \\ $\mathrm{b}_{\text {National University of Singapore }}$ \\ ${ }^{\mathrm{c}}$ University of Hong Kong
}

April 2014

\begin{abstract}
In this paper, we follow the theoretical framework proposed by Djankov et al. (2003) to investigate the role of the state in resolving business disputes and its impact on enterprise performance. Using a survey of private enterprises in China, we first construct an index to quantify the power of the state vis-à-vis the market in resolving business disputes, and then find that enterprises located in regions where the government has a greater relative power enjoy better performance. Our results suggest that the regulatory state has played a positive role in the economic transition in China.
\end{abstract}

Keywords: Dispute Resolution, Power of the State, Enterprise Performance, Regulatory State

JEL Codes: P30, D02, L25

*We would like to thank Professor Simeon Djankov (the Editor) and anonymous referees for insightful comments and suggestions, which have led to significant improvement of the paper. Yi LU acknowledges the support of a research grant from the National University of Singapore (the Ministry of Education's AcRF Tier 1 FY2011-FRC2-005). 


\section{Introduction}

Property rights protection has been found to be of paramount importance in promoting enterprise performance and generating economic growth. ${ }^{1}$ An essential element of property rights protection is the effective resolution of disputes regarding private properties that may arise from business transactions.

According to Djankov et al. (2003), there are three distinct methods of resolving business disputes, i.e., private orderings, private litigation through courts, and regulatory state. In private orderings, market discipline causes business disputes to be resolved through private negotiations. In private litigation through courts, the judicial system helps resolve business disputes according to laws and the government plays a minimal role through invisible hand by providing basic public goods such as law and order. In a regulatory state, the government is heavily involved in commercial dispute resolution where the adjudication reflects the will of the government and the legal framework plays a limited part.

These three methods differ in the power of the state vis-à-vis the market in resolving business disputes (see Figure 1, copied from Figure 1 of Djankov et al. (2003), for illustration). While a strong role of the state helps resolve business disputes expediently thereby minimizing the disorder costs associated with the dispute resolution by the market (Hobbes, 1651), there are concerns about whether the strong state can refrain itself from becoming an expropriator, which could lead to dictatorship costs. Hence it is not clear whether a strong role of the state in resolving business disputes is conducive to the economy.

A systematic empirical investigation of this issue has been challenging because of the difficulty in quantifying the power of the state vis-à-vis the market in resolving business disputes. In this paper, we fill the void by quantifying the power of the state vis-à-vis the market, and investigate how the role of state in resolving business disputes affects enterprise performance.

The data used in this study comes from a survey conducted in 1999 containing a sample of 3,073 privately-owned enterprises in China. In the survey, there is a question regarding how an entrepreneur would resolve business disputes with others. The available answers are: (i) doing nothing; (ii) negotiating between themselves; (iii) seeking help from private networks; (iv) court ruling; and (v) seeking help from the regional government. ${ }^{2}$ We group these answers into three categories corresponding to the three methods for dispute resolution proposed by Djankov et al. (2003): private orderings for answers

\footnotetext{
${ }^{1}$ For example, property rights protection promotes reinvestment rate (Besley, 1995; Johnson, McMillan, and Woodruff, 2002; Cull and Xu, 2005), and productivity (Lu, Png, and Tao, 2013) at the microlevel and leads to economic development (i.e., Acemoglu, Johnson, and Robinson, 2001) at the macrolevel.

${ }^{2}$ Region here refers to 22 provinces, 4 province-level municipalities, and 5 minority autonomous regions in China.
} 
(i), (ii), and (iii); private litigation through courts for answer (iv); and regulatory state for answer (v). We first assign an ordinal value to each enterprise corresponding to the specific category of the response made by the entrepreneur, i.e. value 1 for private orderings, value 2 for private litigation through courts, and value 3 for regulatory state. Then we take the average of such values of enterprises located in a region (weighted by the number of employees) to quantify the power of the state vis-à-vis the market in resolving business disputes in that region, with a higher value indicating a greater power of the state vis-à-vis the market.

We find that private enterprises located in regions with greater power of the state visà-vis the market turn out to have better enterprise performance. These findings remain robust when the regression models are modified to address concerns such as omitted variables and reverse causality issues, alternative measures of the power of the state vis-à-vis the market, and different sub-samples. ${ }^{3}$

Our results suggest that a higher power of the state vis-à-vis the market in adjudicating commercial disputes enhances property rights protection, which in turn promotes enterprise performance. However, it is likely that those enterprises located in regions with a greater power of the state vis-à-vis the market conduct more rent seeking activities and thus achieve better performance by receiving government favors. This is an important issue in assessing whether regulatory state in China serves as a helping hand or grabbing hand for private enterprises. To test whether it is rent seeking that drives our results, we look at various channels through which enterprises might obtain favors through rent seeking activities. There is no evidence that enterprises located in regions with a greater power of the state vis-à-vis the market obtained favors along these channels, which largely rules out the rent seeking interpretation of our results.

Our empirical investigation hinges upon the theoretical framework of Djankov et al. (2003). Specifically, they argue that an increase of disorder costs calls for a greater power of the state vis-à-vis the market in resolving business disputes, whereas an increase of dictatorship costs requires a lower power of the state vis-à-vis the market. Hence, we carry out a comparative static analysis of their theoretical predictions. Indeed, we find that enterprises facing more influential competitors (which implies higher disorder costs) perceive a greater need for the power of the state vis-à-vis the market whereas the opposite is found when enterprises face more expropriation by the governments (which implies higher dictatorship costs).

Our results suggest that the role of the state in resolving business disputes in China

\footnotetext{
${ }^{3}$ Specifically, to deal with omitted variable concern, we control for a host of variables related to entrepreneurial characteristics, enterprise characteristics, regional characteristics, and industry dummies. To further address the potential endogeneity problems, we use the distance between the capital city of each region and the national capital city of China - Beijing - as an instrumental variable for the power of the state vis-à-vis the market in resolving business disputes and carry out the two-stage-least-squares estimation (details are discussed in Section 3.1.2).
} 
is conducive to enterprise performance. One possible explanation is that for the market to resolve business disputes it requires a host of stringent preconditions. Specifically, for private orderings to be an efficient choice, it requires protection of private property rights of one market participant against another. And private litigation hinges upon independent judges who are immune to influences from the rich and the politically-connected. In China, however, the property rights protection for private enterprises was not formally written into the Constitution until 2004. Judges, who were not needed at all in the central-planning system, are newly appointed by the state and their independence is dubious (Clarke, 2007).

One may still be curious to know how China can control dictatorship costs and provide local government officials with incentives to help private entrepreneurs to resolve business disputes. China's central government has adopted fiscal decentralization policy by delegating substantial discretion over regional economies to regional governments while maintaining its strict political control over regional governments, especially in the appointment and promotion of regional government officials. Under this institutional arrangement, the regional government officials have incentives to cultivate satisfactory business environments and promote economic development so as to enhance their private benefits of remaining in power and the chances of being further promoted (e.g., Blanchard and Shleifer, 2001; Qian et al., 2006).

The rest of the paper is organized as follows. Section 2 discusses the data and variables. Empirical results and their interpretations are presented in Section 3. The paper concludes with Section 4.

\section{Data and Variables}

The dataset used in this paper comes from the Private Enterprise Survey in China, which was conducted in 1999. ${ }^{4}$ We focus on private enterprises because in general they do not have government backing and protection, and hence they are most vulnerable to both disorder costs and dictatorship costs. Examining the impacts of different dispute resolution modes on private enterprise performance can most accurately demonstrate whether the government involvement in dispute resolution promotes or hinders enterprise performance.

Multi-stage stratified random sampling method is used in the Survey to achieve a balanced representation across all regions and industries in China. The total number of private enterprises to be surveyed was first determined. Afterwards, six cities/counties

\footnotetext{
${ }^{4}$ This dataset has been used by other scholars, e.g., Bai, Lu, and Tao (2006) in studying the access to bank loans by private enterprises, Li, Meng, and Zhang (2006) in studying entrepreneurs and their political participation, and $\mathrm{Du}, \mathrm{Lu}$, and Tao (2008) in examining the impacts of property rights protection on enterprise diversification.
} 
were selected from each of the thirty-one province-level regions (i.e., the 22 provinces, 4 province-level municipalities and 5 minority autonomous regions), which included the capital city of each region, one district-level city, one county-level city, and three counties. Then the number of private enterprises to be surveyed in each region was calculated as the product of the region's share of private enterprises in the national total with the total number of private enterprises in the survey. The same method was used to determine the number of sample enterprises in every city/county or industry. Finally, private enterprises were randomly chosen from each sub-sample.

The initial sample size is 3,073 enterprises. After deleting observations with no industry code, no output or no employment figure, we obtain the final sample of 2,616 private enterprises. Table 1 shows the distribution of the initial sample and final sample across regions in China as well as the percentage of enterprises with complete information. Jiangsu, Shandong and Guangdong have the largest numbers of observations while Tibet, Qinghai and Ningxia have the smallest. The average percentage of enterprises with complete information across regions is $83.72 \%$ with a standard deviation of 0.086 , which means the final sample is representative.

The dependent variable for our study is Enterprise Performance, measured by the logarithm of output per worker. ${ }^{5}$ This is consistent with the convention in the literature investigating the impacts of the quality of institutions on economic performance and growth.

The key explanatory variable in our study measures the power of the state vis-à-vis the market in resolving business disputes in each region. According to Djankov et al. (2003), there are three distinct methods for resolving business disputes, i.e., private orderings, private litigation through courts, and regulatory state, with an increasing power of the state vis-à-vis the market. In the Survey there is a question regarding how private entrepreneurs would deal with business disputes. The available answers are: (i) doing nothing; (ii) negotiating between themselves; (iii) seeking help from private networks; (iv) court ruling; and (v) seeking help from regional government. Enterprises could only pick one out of the five possible choices, and thus the chosen one is presumably the most frequently used or the most important method for resolving business disputes. We group them into three categories corresponding closely to the three methods for resolving business disputes: private orderings for answers (i), (ii), and (iii); private litigation through courts for answer (iv), and regulatory state for answer (v).

We then assign an ordinal value to each enterprise corresponding to the specific category of the response made by the entrepreneur, i.e. value 1 for private orderings, value

\footnotetext{
${ }^{5}$ We can also use returns on capital or total factor productivity to measure enterprise performance. However, due to a lot of missing information on capital, we mainly use labor productivity for measuring enterprise performance in this study. In one of our robustness checks, we include the logarithm of capital-labor ratio as a control for enterprise performance in a reduced sample. That robustness check is equivalent to the use of total factor productivity as the measure of enterprise performance.
} 
2 for private litigation through courts, and value 3 for regulatory state. A variable called Power of the State vis-à-vis the Market in resolving business disputes is thus constructed for each region based on the average value of the power of the state vis-à-vis the market perceived by the enterprises located in that region (weighted by the number of employees), ${ }^{6}$ with a higher value indicating a greater power of the state vis-à-vis the market. There are variations in the power of the state vis-à-vis the market in resolving business disputes across China's regions, with a mean of 1.31 and a standard deviation of 0.27 .

To alleviate the concern of omitted variables, we include a host of variables that may affect enterprise performance. The background and capability of entrepreneurs can be important determinants of private enterprise performance. Therefore, we include some conventional managerial human capital variables like Age (the age of the entrepreneur by the end of 1999), Education (years of formal schooling), and Managerial Experiences (the number of years an entrepreneur had held a managerial position before he or she started his or her own business), and some political capital variables such as CPC Membership (a dummy variable taking value one if the entrepreneur is a member of the Chinese People's Congress and zero otherwise) and CPPCC Membership (a dummy variable taking value one if the entrepreneur is a member of the Chinese People's Political Consultative Conference and zero otherwise), Government Cadre (a dummy variable taking value one if the entrepreneur used to be a government official and zero otherwise), and SOE Cadre (a dummy variable taking value one if the entrepreneur used to be a manager in stateowned enterprises and zero otherwise). We also control for enterprise characteristics, such as Enterprise Size (the logarithm of the number of employees in each enterprise) and Enterprise Age (the logarithm of the number of years an enterprise had been in operation by the end of 1999), that have been suggested to be important for enterprise performance, and include industry dummies. Finally, regional characteristics such as Logarithm of GDP per capita and Logarithm of Population are also included.

To further address the potential endogeneity issue, we adopt the instrumental variable approach. Specifically, we use the distance between the capital city of each region and the national capital city of China - Beijing - as an instrumental variable for the power of the state vis-à-vis the market (details will be discussed in Section 3.1.2).

Summary statistics of all key variables are given in Table 2 .

\footnotetext{
${ }^{6}$ Weighted averages (by either the number of employees or output) are used to take into account the possibility that larger enterprises could be more likely to use "seeking government help" or "court ruling" for resolving business disputes as their larger business proceeds could more likely cover the institutional fixed costs in dealing with courts and government entities. Nonetheless the qualitative nature of our main results remains when no weights are used.
} 


\section{Empirical Analysis}

\subsection{Main Results}

\subsubsection{OLS Estimates}

To investigate the impacts of the power of the state vis-à-vis the market in resolving business disputes on enterprise performance, we estimate the following equation:

$$
y_{e i r}=\alpha+\beta G_{r}+X_{e i r}^{\prime} \gamma+\varepsilon_{e i r}
$$

where $y_{\text {eir }}$ is the performance of enterprise $e$ in region $r$ and industry $i, G_{r}$ represents the power of the state vis-à-vis the market in resolving business disputes in region $r, X_{\text {eir }}^{\prime}$ is a vector of control variables (i.e., entrepreneurial and enterprise characteristics, regional characteristics, and industry dummies), and $\varepsilon_{e i r}$ is a random error term. ${ }^{7}$

Table 3 shows the ordinary-least-squares (OLS) estimation results. Column 1 reports our main regression result that Power of the State vis-à-vis the Market produces a positive and statistically significant effect on enterprise performance.

Our results are robust when control variables related to industry dummies, regional characteristics, entrepreneurial characteristics and enterprise characteristics are included stepwisely (Columns 2-5 of Table 3). The coefficients of control variables also make sense. It is found that an entrepreneur with a higher level of education and more years of managerial experience in state-owned enterprises enjoys better enterprise performance. It is also found that smaller enterprises exhibit higher impetus to growth.

The basic message conveyed by Table 3 is clear: A greater power of the state vis-à-vis the market in resolving business disputes enhances enterprise performance.

\subsubsection{Instrumental Variable Estimates}

The estimation results in Table 3 could be biased due to the endogeneity issues. For example, we may not exhaust all the possible variables that correlate with both the power of the state vis-à-vis the market in resolving business disputes and enterprise performance. Meanwhile, enterprises with better performance could receive more attention and "protection" from local governments and therefore they seek government help in dispute settlements more often.

To address these potential endogeneity issues, we adopt the instrumental variable estimation strategy. Specifically, the instrumental variable used is the distance between

\footnotetext{
${ }^{7}$ In general the standard errors for micro-level data need to be adjusted for possible clustering to deal with the heteroskadasticity problem (e.g., Liang and Zeger, 1986). However, in practice, when the number of clusters is small (i.e., less than 42), the clustered standard errors could be misleading (e.g., Wooldridge, 2003). As the number of clusters in our study is 31, we follow Angrist and Lang (2004) to use the White-robust standard errors.
} 
the capital city of each region and the national capital city of China, Beijing, where the central government is located.

Over thousands of years the Chinese political system has been characterized by the centralization of political power during most of the periods. The central government keeps the power to appoint regional government officials. It also issues various laws and national ordinances for them to guide the regional administrations. Because China is a large country with substantial variations in endowments, socioeconomic development and culture across regions, however, unified and comprehensive laws and national ordinances may be ill-suited for the local conditions of some regions. Thus it is essential for regional government officials to interpret and enforce laws and national ordinances so as to make them more adapted to local circumstances. In the meantime, the fast changes in socioeconomic environment experienced by China in its transition toward a market economy in recent decades induce many new cases that require regional government officials to judge whether they comply with government reform policies. Hence, the proactive intervention of regional government officials is particularly needed in helping private firms resolve various business disputes and creating a friendly business environment. Indeed, regional bureaucrats have been playing a decisive role in civil and criminal lawsuits throughout the Chinese history. In the pre-modern society, regional government officials themselves exercised judicial power. Even in the eras of the Republic of China and the Communist regime, the judicial system has still largely relied on the will of regional government officials.

Furthermore, it is more costly for the central government to frequently inspect local situations and monitor local bureaucrats in regions farther away from Beijing. Consequently, the higher degree of information asymmetry makes the central government more reliant on local officials in regional governance. Thus regional government officials in regions farther away from Beijing have greater de facto powers in running the regional economy, including adjudicating commercial disputes. In particular, regional bureaucrats in regions farther away from Beijing are subject to less central control and have a greater degree of freedom in interpreting and enforcing laws and national ordinances. Indeed there is an old Chinese saying: "The Mountains Are High and the Emperor is Far Away." It is thus expected that in regions farther away from Beijing, the powers of the state vis-à-vis the market in those regions are greater.

Figure 2 shows the positive correlation between the power of the state vis-à-vis the market in resolving business disputes in a region and the distance between that regional capital city and Beijing. ${ }^{8}$ Table 4 presents the two-stage-least-squares estimation results. The first-stage regression results reported in Column 1 show that the distance between

\footnotetext{
${ }^{8}$ For the four province-level municipalities directly under the central government (i.e., Beijing, Tianjing, Shanghai, and Chongqing), the instrumental variable is simply their distance from Beijing, with that for Beijing equal to zero.
} 
regional capital city and Beijing has a positive and statistically significant coefficient, which confirms our argument that the power of the state vis-à-vis the market is greater in regions farther away from Beijing. The relevance condition for our instrumental variable is further confirmed by the Anderson canonical LR statistic. And the Cragg-Donald F-statistic rules out the concern for weak instrument. ${ }^{9}$

Column 2 of Table 4 presents the second-stage regression results. The results reinforce our earlier findings and show that the power of the state vis-à-vis the market in resolving business disputes has a positive and statistically significant causal effect on enterprise performance. Our main results - the statistically significant positive impacts of the power of the state vis-à-vis the market on enterprise performance - remain robust when industry dummies, regional characteristics, entrepreneurial characteristics and enterprise characteristics are included as controls (in Columns 3-4 of Table 4).

In addition to satisfying the relevance condition, our instrumental variable also needs to meet the orthogonality condition, i.e., it does not affect enterprise performance through channels other than the power of the state vis-à-vis the market. This, however, should not be a concern in our case, as there is no obvious correlation between the distance away from Beijing and other regional characteristics that conceivably affect enterprise performance. The national capital, Beijing, is located in the northern-central area of the country with many regions lying to the north, south, west or east of the capital. For example, Shanghai has similar distance from Beijing as do Wuhan (the capital city of Hubei province) and Harbin (the capital city of Heilongjiang province). And Nanjing (the capital city of Jiangsu province) and Xi'an (the capital city of Shaanxi province) have similar distances from Beijing (for more information and comparison about the distance of regional capital from Beijing for each region, please see Figure 2). However, these regions have striking differences in regional characteristics, such as economic performance, population, education, landscape, resource endowments, climate conditions, openness to international trade and investment, and financial market development. ${ }^{10}$ Therefore, distance from Beijing does not suggest any particular patterns of regional characteristics, which implies that our instrumental variable meets the orthogonality condition.

\subsubsection{Limitation of the Dataset}

In this study, we examine the variation in the power of the state vis-à-vis the market at the province level and its impacts on firm performance. We admit that the administration organs and the courts at the prefecture-level cities and even counties play an important part in resolving business disputes. For example, according to Articles 17 and 18 of the

\footnotetext{
${ }^{9}$ The Cragg-Donald F-statistic values for our regressions are significantly above the value of 10 , which is considered as the critical value by Staiger and Stock (1997).

${ }^{10}$ Indeed, the regression results are qualitatively similar when these regional characteristics are included. Results are available upon request.
} 
Civil Procedure Law of the People's Republic of China, the basic people's court at the county shall have jurisdiction as court of first instance over civil cases unless otherwise provided. The intermediate people's courts at the prefecture level are responsible for the appeal cases, and serve as courts of first instance for some important and influential cases. At the same time, administrative intermediation conducted by local governments at the prefecture or county level plays an instrumental role in business dispute resolution. ${ }^{11}$ Thus, local governments and courts at the prefecture and county levels have handled the majority of business dispute cases. It will therefore be ideal if we can examine the variation in the power of the state vis-à-vis the market at the prefecture or county level. Unfortunately, the dataset does not contain detailed information on the geographical location of the private firms surveyed.

Despite the limitations of the dataset, our analysis based on the province-level regions, in our opinion, can still provide useful information and insights. Firstly, we look at the court system in China. It is true that the county-level basic people's courts and prefecture-city level intermediate people's courts have handled most of the commercial dispute cases, but they are almost always routine cases. We can claim that the provincelevel higher people's courts still play a leading role in the adjudication of commercial dispute cases on the basis of the following considerations. (1) According to Article 16 of the Organization Law of People's Courts of the People's Republic of China, the provincelevel higher people's courts supervise the trial of cases in the intermediate people's courts and basic people's courts in the region. (2) According to Articles 18 and 19 of the Civil Procedure Law of the People's Republic of China, for some important non-routine cases, e.g., major cases involving foreign elements, cases that have major impacts on the area under its jurisdiction, etc., the prefecture-city level intermediate people's courts are the courts of first instance, and the higher people's courts directly handle appeal cases. For some civil cases that have major impacts on the region, the higher people's court has jurisdiction as court of first instance. (3) The higher people's court plays an instrumental role in guiding the judiciary system in the region. Typically, the supreme people's court gives instructions to higher people's courts in different regions once new interpretations of laws or any new issues in law implementations emerge. ${ }^{12}$ The higher courts then make re-interpretations and convey them to lower courts in the region. Thus, the province-level higher courts have played a leading part in guiding the operation of the judicial system

\footnotetext{
11 "The Opinions on the Strengthening of the Role of Governments in Building a Law-Based Society" issued by China's State Council in October 2010 reconfirmed the practice of administrative intermediation of civil disputes by local governments at the provincial, prefecture or county level. Many provinces such as Jiangxi, Ningxia, Sichuan, etc. have issued guidance opinions to their prefecture, county and township level governments on the procedure of administrative intermediation of civil disputes.

${ }^{12}$ For example, the Supreme People's Court issued in March 2005 a notice to higher courts in different provinces regarding the protection of creditors/lenders' claims and prevention of the value losses of state-owned assets in the adjudication of civil cases. The higher courts in different regions were asked to implement this new guidance.
} 
in the region.

Secondly, we look at the government apparatus (i.e., the administration organs) in China. Provincial governments have been active in regulating market economy and promoting economic development. (1) As mentioned above, one plausible explanation of the helping hand offered by China's governments is that fiscal decentralization has motivated local bureaucrats to improve business environment and nurture private enterprise development. The fiscal contracting system (1978-1993) and the tax sharing system implemented since 1994 have mainly dealt with the intergovernmental fiscal relations between the central government and the provincial governments. The fiscal relations between the provincial government and the prefecture-level cities and counties within the province are left to the negotiation between the provincial governments and lower-level local governments. ${ }^{13}$ Thus, provincial governments are the primary beneficiaries from fiscal decentralization and are expected to have particularly strong incentives to promote a relatively friendly business environment for private enterprise development. The policies and guidance set by provincial governments are expected to be instrumental in shaping the practices of administrative intermediation of business disputes carried out by prefecture, county and township governments in the region. (2) Under the Chinese government system, the central government guides the province-level governments in the implementation of new policies and development initiatives. ${ }^{14}$ The provincial governments in turn adapt these policies to local situations to some degree and further instruct lower level governments to fulfill different tasks to comply with the central government's policies.

In this sense, the variation at the province level can still capture much of the disparity in the power of the state vis-à-vis the market in China. Actually our tests may well underestimate the impacts of the power of the state vis-à-vis the market (i.e., slanted in favor of failing to reject the null) because we lose quite much of the variation at the prefecture-city or county level.

\subsubsection{Robustness Checks}

First, we investigate whether our main results are robust to alternative ordinal values assigned to the three methods for resolving business disputes, i.e., private orderings, private litigations through courts, and regulatory state in constructing the index of the power of the state vis-à-vis the market. In Section 2, we assign values 1-3 to these three methods with the purpose of showing an increasing power of the state vis-à-vis the market. One may have concern that the ordinal values assigned look somewhat arbitrary.

\footnotetext{
${ }^{13}$ The Ministry of Finance of China has explained this point clearly in its explanation of the current status of the tax sharing system. The document in Chinese is available at http://www.mof.gov.cn/zhuantihuigu/czjbqk2011/cztz2011/201208/t20120831_679806.html.

${ }^{14}$ For instance, to curb the property market bubble, the State Council has issued quite a few ordinances and guidance notices to provincial governments since 2009, and asked provincial governments to organize the implementation of the policies.
} 
To make sure that the absolute value assigned to each category does not matter but the relative ranking is important, we experiment with different values attached to each method. In the first experiment, we give the value of 1 to private orderings, 2 to private litigations through courts and 10 to regulatory state. In the second experiment, we let private orderings be 1 , private litigation be 9 and regulatory state be 10 . In the third experiment, we assign values of 1,5 and 10 to private orderings, private litigations and regulatory state, respectively.

Columns 2-4 of Table 5 summarize the estimation results when the above three alternative constructions for the index of the power of the state vis-à-vis the market are used, while Column 1 simply replicates Column 4 of Table 4 as the benchmark for comparison. All the control variables are included in the regressions but not reported to save space. It is clear that our main results reported in Tables 3-4 remain robust when we vary the values assigned to different methods for resolving business disputes, which confirms that the exact value assigned to each method does not matter, but the relative ranking of the three methods in terms of the power of the state vis-à-vis the market is important.

Second, we use two alternative measures of the power of the state vis-à-vis the market. One is the index of regional progress in marketization constructed by Fan, Wang, and Zhu (2003). The Fan-Wang-Zhu index gauges the development of market economy in each region on the basis of many important aspects encompassing the degree of government intervention in business operation and resource allocation, the development of the non-state sector, the development of the product markets and factor markets, and the development of market intermediaries and legal institutions. A higher value of the index indicates a better development of market economy and less state control of the regional economy. The other measure is the ratio of government consumption over regional GDP, with a higher value indicating a greater power of government in the economy. ${ }^{15}$ The index of the power of the state vis-à-vis the market in our earlier study focuses specifically on the regional government officials' role in resolving commercial disputes. The two alternative indices we look at here cover more broadly the part played by regional government officials in the local economy. Thus the information contained in these two indices is expected to provide some complementary messages regarding how involved the regional government officials have been in the Chinese economy.

Column 1 of Table 6 shows that the Fan-Wang-Zhu index is negatively correlated with the distance between regional capital city and Beijing (in Panel B of Column 1), and it has a negative and statistically significant causal effect on enterprise performance (in Panel A of Column 1). Column 2 of Table 6 shows that the ratio of government consumption over regional GDP is positively correlated with the distance between regional capital city and

\footnotetext{
${ }^{15}$ The correlation between Power of the State vis-à-vis the Market and the Fan-Wang-Zhu index is -0.46, whereas that between Power of the State vis-à-vis the Market and the ratio of government consumption over regional GDP is 0.30 .
} 
Beijing (in Panel B of Column 2), and it has a positive and statistically significant causal effect on enterprise performance (in Panel A of Column 2). These results are consistent with our earlier findings.

Third, we test the robustness of our results using two subsamples of our dataset. In the Survey, there is a question regarding the identity of the party with whom an enterprise is having business disputes. It could be: with customers, or suppliers, or government agencies. As disputes with government agencies could be qualitatively different from those with commercial partners, we restrict our sample to those observations with only commercial disputes. Column 3 of Table 6 shows that our central results remain robust to the use of this subsample. Meanwhile, as Qinghai and Ningxia have very few observations yet very high values in the indices of the power of the state vis-à-vis the market (see Table 1 and Figure 2 for details), we thus exclude these two regions from our sample, and test if our results are possibly affected by these outliers. As shown in Column 4 of Table 6, our main results are robust to this subsample.

Fourth, it has been argued that enterprise performance could be affected by the capital-labor ratio. Unfortunately, there is quite a lot of missing information on the amount of capital employed by enterprises in our dataset. Nonetheless, we conduct a robustness test based on a reduced sample by including the logarithm of the capital-labor ratio as a control variable for enterprise performance. As shown in Column 5 of Table 6 , our main results still hold in this subsample.

Lastly, we use enterprise-level perception, rather than the regional average perception, of the power of the state vis-à-vis the market in resolving business disputes as the key explanatory variable. As shown in Column 6 of Table 6, our main results remain, i.e., the power of the state vis-à-vis the market continues to produce positive and statistically significant impacts on enterprise performance.

Overall, our robustness analysis as summarized in Tables 5-6 confirms our earlier finding that the power of the state vis-à-vis the market in resolving business disputes has a positive and significant causal effect on enterprise performance in China.

\subsection{Does Rent Seeking Drive Our Results?}

We interpret our results as that the role of the state vis-à-vis the market has a positive impact on enterprise performance. However, there could be an alternative interpretation as that those enterprises located in regions with a greater power of the state vis-à-vis the market conduct more rent seeking activities and thus achieve better performance through securing favors and protection from regional bureaucrats. Certainly, asking for government's help in resolving business disputes could possibly reflect rent seeking activity.

Presumably if rent seeking is the driving force, an enterprise located in a region with a greater power of the state vis-à-vis the market would most likely obtain favors from 
the regional government in the forms of lower production costs and/or easier sales of its products and services. In the Survey, there are questions regarding whether an enterprise has difficulties in the following six aspects of the enterprise operation: input procurement, availability of production locations, supply of electricity and water, recruitment of skilled labor, sales of products, and sales of services. The answers to these questions range from 1 to 3 , with a higher value indicating fewer difficulties in the specific operation. In addition, we use the percentage of outstanding bank loans in an enterprise's total assets to measure the access to external finance. We conduct two-stage-least-squares regressions of these seven aspects of the enterprise operation on Power of the State vis-à-vis the Market with the instrumental variable being the distance between the regional capital city and the national capital city of China, Beijing. As shown in Columns 1-7 of Table 7, all of the seven estimated coefficients are negative. These results suggest that enterprises located in regions with a greater power of the state vis-à-vis the market in resolving business disputes do not obtain any favors in the forms of lower production costs and/or easier sales of its products or services.

Alternatively, we carry out another empirical test, in which these seven channel variables are included as additional control variables in the regression of Enterprise Performance on Power of the State vis-à-vis the Market. If the magnitude and statistical significance of the estimated coefficient on Power of the State vis-à-vis the Market diminishes to a substantial extent and the channel variables remain statistically significant with the expected sign, then we can conclude that a higher degree of government involvement in business dispute resolution helps enhance enterprise performance mainly through rent seeking. The regression results, not reported here but available upon request, show that there are no changes in the magnitude and significance of our key explanatory variable, Power of the State vis-à-vis the Market. This suggests that the impact of the government in commercial dispute resolution on enterprise performance does not work through any of these channels.

\subsection{Checks on the Theoretical Framework of the Empirical Analy- sis}

Our above empirical analysis is based on the theoretical framework proposed by Djankov et al. (2003), which predicts that an increase of disorder costs (i.e., expropriation by thieves, competitors, or tort-feasors) calls for a greater power of the state vis-à-vis the market in resolving business disputes whereas an increase of dictatorship costs (i.e., expropriation by governments) requires a lower power of the state vis-à-vis the market. As a further check on the validity of our empirical analysis, we test if these general predictions are borne out in our data set. Indeed, the Survey contains information that allows us to gauge the disorder costs and dictatorship costs perceived by entrepreneurs, based on 
which we can carry out a comparative statics analysis.

In the Survey, there is a question asking entrepreneurs whether there exist influential producers in their industries that enjoy favorable market positions to facilitate input procurement and output sales and therefore they are dominant players in the market. It is expected that when facing such dominant competitors, private enterprises encounter higher disorder $\operatorname{costs}^{16}$ and perceive a greater need for government regulations to alleviate market disorders. We construct a dummy variable called Influential Competitors, and carry out an Ordered Probit regression of Power of the State vis-à-vis the Market on Influential Competitors along with a set of control variables. As shown in Column 1 of Table 8, Influential Competitors has a positive and statistically significant estimated coefficient, which implies that the increase of disorder costs leads to a rise in the power of the state vis-à-vis the market as predicted by Djankov et al. (2003).

In the Survey, there is another question asking entrepreneurs about the amount of extralegal payments to the government made by the enterprises. Extralegal payments to the government measure the extent of government expropriation. It is thus expected that enterprises facing higher extralegal payments to the government encounter higher dictatorship costs and perceive a lesser need for the power of the state vis-à-vis the market such as less government regulation. We then construct a variable called Ratio of Extralegal Payments (measured as the ratio of extralegal payments to the government by the enterprise over its profit) and use it as a proxy for dictatorship costs, with a higher value indicating greater dictatorship costs. We carry out an Ordered Probit regression of Power of the State vis-à-vis the Market on Ratio of Extralegal Payments along with a set of control variables. As shown in Column 2 of Table 8, Ratio of Extralegal Payments has a negative and statistically significant estimated coefficient, which implies that the increase of dictatorship costs leads to a fall of the power of the state vis-à-vis the market as predicted by Djankov et al. (2003).

\section{Conclusion}

Effective resolution of business disputes associated with private properties is the key to property rights protection, which in turns plays a fundamental role in promoting economic performance. There are various methods for resolving business disputes (i.e., private orderings, private litigation through courts and regulatory state), characterized by the different degree of the power of the state vis-à-vis the market. As argued by Djankov et al. (2003), having a stronger role of the state vis-à-vis the market in resolving business disputes brings costs (increase in the dictatorship costs) as well as benefits (decrease in the disorder costs).

\footnotetext{
${ }^{16}$ For example, private enterprises often encounter difficulties in collecting payments from large influential enterprises with whom they have businesses.
} 
In this paper, we investigate the role of the state vis-à-vis the market in resolving business disputes, and its impact on enterprise performance. Specifically, using data from a survey of 3,073 private enterprises in China, we construct an index to quantify the power of the state vis-à-vis the market in resolving business disputes based on the theoretical framework proposed by Djankov et al. (2003). We find that the power of the state vis-à-vis the market in resolving business disputes has a positive and statistically significant causal impact on enterprise performance. Our results are robust to a set of controls related to entrepreneurial, enterprise, regional and industrial characteristics, and to the use of instrumental variable estimation. Our findings suggest that China has implemented a regulatory state model in commercial dispute resolution which creates a friendly business environment for private enterprises.

Our findings have general implications for other transition and developing economies. These economies have carried out economic liberalization to move towards a market economy in the past few decades. During the transition towards the market economy, however, these economies lacked the sophisticated institutions for the market and the judiciary, i.e., private ordering and private litigation through courts, to resolve business disputes effectively. This may explain why some transition and developing economies did not display impressive economic performance. Our findings suggest that they should keep a strong role of the state in resolving business disputes and gradually diminish the role of the state with the progress in the establishment and sophistication of the market institutions. However, in keeping a strong role for the state in commercial dispute adjudication, a transition and developing economy needs to strengthen its institutions to limit bureaucratic corruption and rent-seeking activities so as to turn state intervention into a helping hand for private businesses. The relative success of China's regulatory state model in this respect is built upon its political system that effectively encourages local bureaucrats to cultivate a friendly business environment.

\section{References}

[1] Acemoglu, Daron, Simon Johnson, and James A. Robinson. 2001. "The Colonial Origins of Comparative Development: An Empirical Investigation", American Economic Review 91, 1369-1401.

[2] Angrist, Joshua and Kevin Lang. 2004. "Does School Integration Generate Peer Effects? Evidence from Boston's Metco Program", American Economic Review 94, 1613-1634.

[3] Bai, Chong-En, Jiangyong Lu, and Zhigang Tao. 2006. "Property Rights Protection and Access to Bank Loans: Evidence from Private Enterprises in China", Economics of Transition 14, 611-628. 
[4] Besley, Timothy. 1995. "Property Rights and Investment Incentives: Theory and Evidence from Ghana", Journal of Political Economy 103, 903-937.

[5] Blanchard, Olivier and Andrei Shleifer. 2001. "Federalism With and Without Political Centralization: China Versus Russia", IMF Staff Papers 48, 171-179.

[6] Clarke, Donald. 2007. "The Chinese Legal System Since 1995: Steady Development, Striking Continuities", China Quarterly 191, 555-566.

[7] Cull, Robert, and Lixin Colin Xu. 2005. "Institutions, Ownership, and Finance: the Determinant of Profit Reinvestment among Chinese Firms", Journal of Financial Economics 77, 117-146.

[8] Du, Julan, Yi Lu, and Zhigang Tao. 2008. "Property Rights Protection and Firm Diversification: Evidence from China's Private Enterprises", working paper.

[9] Djankov, Simeon, Edward Glaeser, Rafael La Porta, Florencio Lopez-de-Silanes, and Andrei Shleifer. 2003. "The New Comparative Economics", Journal of Comparative Economics 31, 595-619.

[10] Fan, Gang, Xiaolu Wang, and Henpeng Zhu. 2003. Reports on the Relative Progress of Marketization in Different Regions in China, Economic Science Publishing House, China.

[11] Hobbes, Thomas. 1651. Leviathan, reprinted in: R. Tuck ed. Leviathan, Cambridge University Press: New York, NY.

[12] Johnson, Simon, John McMillan, and Christopher Woodruff. 2002. "Property Rights and Finance", American Economic Review 22, 1335-1356.

[13] Li, Hongbin, Lingsheng Meng, and Junsen Zhang. 2006. "Why Do Entrepreneurs Enter Politics", Economic Inquiry 44, 559-578.

[14] Liang, Kung-Yee and Scott L. Zeger. 1986. "Longitudinal Data Analysis Using Generalized Linear Models", Biometrika 73, 13-22.

[15] Lu, Yi, Ivan Png, and Zhigang Tao. 2013. "Do Institutions not Matter in China? Evidence from Manufacturing Enterprises", Journal of Comparative Economics 41, 74-90.

[16] Qian, Yingyi, Geràld Roland, and Chenggang Xu. 2006. "Coordination and Experimentation in M-form and U-form Organizations", Journal of Political Economy 114, 366-402. 
[17] Staiger, Douglas and James Stock. 1997. "Instrumental Variables Regression with Weak Instruments", Econometrica 65, 557-586.

[18] Wooldridge, Jeffrey M. 2003. "Cluster-Sample Methods in Applied Econometrics", American Economic Review 93, 133-138. 